\title{
Stakeholders' Perception as Support for Forest Landscape Planning
}

\author{
Isabella De Meo, ${ }^{1}$ Maria Giulia Cantiani, ${ }^{2}$ Fabrizio Ferretti, ${ }^{3}$ and Alessandro Paletto ${ }^{1}$ \\ ${ }^{1}$ Agricultural Research Council-Forest Monitoring and Planning Research Unit (CRA-MPF), P.za Nicolini 6, \\ Villazzano, 38124 Trento, Italy \\ ${ }^{2}$ Forest Ecology Laboratory, Civil and Environmental Engineering Department, University of Trento, Via Mesiano 77, \\ Mesiano, 38050 Trento, Italy \\ ${ }^{3}$ Agricultural Research Council-Appennine Forestry Research Unit (CRA-SFA), Via Bellini 8, 86170 Isernia, Italy
}

Correspondence should be addressed to Alessandro Paletto, alessandro.paletto@entecra.it

Received 7 July 2011; Revised 1 September 2011; Accepted 1 September 2011

Academic Editor: Pavlos Kassomenos

Copyright (C) 2011 Isabella De Meo et al. This is an open access article distributed under the Creative Commons Attribution License, which permits unrestricted use, distribution, and reproduction in any medium, provided the original work is properly cited.

\begin{abstract}
Social sustainability is a key concept introduced in recent decades by international environmental and forestry policies. The paper illustrates the process of stakeholder consultation for the definition of the objectives of the forest landscape plan conducted in a district of the Italian Apennines. Special attention was given to the farmers group, by reason of the great importance of wood pasture in the management system of this area. The results show that the majority of the interviewees feel a strong bond with their territory and with the traditional activities still carried out there, such as forest grazing. However, there are internal differences within the group, mostly linked to age and territory of origin. The multiple correspondence analysis (MCA) supported the investigation of these differences and the analysis of the relationship between farmers and their territory. Information emerged from the interviews with farmers allowed a better understanding of the dynamics of the territory and was revealed to be useful for the development of the forest landscape plan.
\end{abstract}

\section{Introduction}

Principle 10 of the United Nations Conference on Environment and Development (UNCED) is a key milestone towards increased public participation in environmental management decisions. Principle 10 stresses the issue of keeping local communities informed which becomes more and more relevant as a central component of social and environmental sustainability. As a result, the social dimension has become a fundamental element of sustainable forest management (SFM) $[1,2]$. In this framework, local community participation and involvement in the decision-making processin particular in the definition of forest management strategies-has been developed [3-5].

Heightened sensibility, particularly towards issues such as sustainability, together with an increased awareness of the threat posed to the environment, a threat that in the past was largely dismissed, has intensified public opinion to the point where citizens claim the right not only to express their views in regard to issues concerning the forest, but also to be able to influence directly such issues.

This being the case, forest policy and planning today needs to be aware of people's perception of the forest and of the issues related to this topic, and to take into consideration the entire range of values attributed thereto [6-11].

The case study concerns an area of the Italian Apennines (Basilicata Region, Southern Italy) in which local forest managers are developing forest landscape planning.

The objective of the research is to analyse the perception of farmers with respect to the forests and to certain issues deeply tied to forest management and planning. Farmers are key stakeholders in the local rural context. In fact, the grazing of livestock - in particular cattle grazing - strongly conditions the management of forests and is responsible for conflict among institutional organisations, forest owners, and farmers. 
The research can be useful to provide forest policy and planning managers with insight into how local communities actually perceive forest management.

\section{Materials and Methods}

2.1. Study Site. The study area is the Comunità Montana Collina Materana (the Comunità Montana is the Italian administrative body that coordinates the municipalities located in the mountainous areas and is responsible for administration and economic development.) $\left(40^{\circ} 29^{\prime} 30^{\prime \prime} \mathrm{N}\right.$; $\left.16^{\circ} 09^{\prime} 20^{\prime \prime} \mathrm{E}\right)$, located in the central-western part of the Matera Province in the Basilicata Region, Southern Italy (Figure 1). The territory of the Comunità Montana, occupying about $60.784 \mathrm{ha}$, is divided into seven municipalities.

The forest covers a surface of 22.221 ha, that is, $36.5 \%$ of the territory. Privately owned land amounts to $64.3 \%$, whereas the remaining $35.7 \%$ belongs to public administrations. Forest management is strongly influenced by the type of property; public forests are usually managed by public organisations or forestry cooperatives. In private forests, there are two different situations: traditional management for household firewood production and unmanaged forests.

The main forest types are Turkey oak (Quercus cerris L.) dominant forest, Downy oak (Quercus pubescens Willd.) dominant forest, and Holm oak (Quercus ilex L.) dominant forest. The large diversity of forest types is attributed to the great variability in morphology, altitude, and lithology of the area. In the eastern part of the territory, the forests are more scattered, providing space for agricultural lands, shrub lands, and bad lands.

Wood pasture has been practiced in the Materana Mountain since the Middle Ages, as in other areas of Europe. It is essentially a system of land management where trees are grown, but with grazing by large herbivores (domesticated, semidomesticated, wild, or a combination) [12-15]. Wood pasture represents the most ancient management system in a "multifunctional landscape" [14] where crops, pastures, wood pastures, forests, and grazed forests represent the elements of a mosaic in which livestock is a key component.

Grazing by livestock, a practice that has declined in other areas of Italy, still represents an important use of certain forest types in Southern Italy. These lands produce palatable and nutritious forage for summer grazing, supplementing the limited amount of spring-fall grassland range.

In the Collina Materana, oak forests are the most suitable forest formations for this type of grazing as they are characterised by a well-developed herbaceous and shrubby undergrowth, sufficient to feed the livestock (Figure 2).

Seldom farmers hold enough land to graze their cattles, by reason of the fact that private property is extremely fragmented and pulverized. In general, only public organisations (Region and Municipalities) are able to lease land to farmers with long-term leases. The opportunity to graze cattle on public land is very important for farmers, but local survey highlights that vegetation is clearly damaged by an overabundance of livestock. For this reason, it is important to define new management rules to combine forest grazing and forest preservation, adapting the management of the forests for multiple use. These rules are a necessary premise to limit conflicts among public organisations, forest owners, and farmers.

Continued forest grazing, carried out excessively, is very closely connected to the widespread presence of forest formations degraded with irregular structures, and species reduction and simplification. The widespread phenomenon of soil compaction and damage caused by animal paths can likewise be imputed to an overabundance of livestock.

The population of the Collina Materana numbers 12.040 inhabitants, and the demographic density is 19.8 people/ $\mathrm{km}^{2}$. Considering the age distribution, the population is concentrated in the adult classes $(10.6 \%$ in $0-14$ years, $61.5 \%$ in 15-64 years, and $28.0 \%$ in the class over 65 years), while the old age index is $275.6 \%$, and the average age is 46.8 years. The rural sector plays quite an important role in the economic structure of the Comunità Montana, employing $24 \%$ of the active population, whereas the national average is $8 \%$, and the European average is $4-5 \%$. Moreover, most of the agricultural enterprises (35.8\%) are small-sized farms that combine agricultural and husbandry activities.

Conversely, the industrial sector is extremely weak, as is demonstrated by the very scarce presence of factories operating in the area. So, too, is the tourist sector, which has not shown any significant development so far.

2.2. Research Survey. Forest landscape planning in the Comunità Montana is decided upon by means of a participatory process: stakeholders are involved all along the decision-making process so that management guidelines are defined by decision makers and local communities through a shared process. Specifically, the consultation approach has been considered the most suitable method of participation for involving various stakeholders and for highlighting the preferences and perceptions of local actors.

The first phase of the consultation is aimed at gathering the perceptions, opinions, and expectations of those actors who are in some way and at different levels interested in the general impact of ongoing planning in the territory. The final goal, in this phase, is to highlight the problems and opportunities in the area and to use the data gathered from the perceptive investigation, along with the information retrieved from the inventory taken of the forest formations, to elaborate the first draft of the planning alternatives.

Through a preliminary stakeholders analysis, a total of 63 stakeholders have been identified.

Among the people interviewed, a distinction is made between farmers and other actors, by reason of the fact that farmers represent the most relevant social group interested in the effect of ongoing landscape planning. In fact, forest grazing strongly conditions the management of forests and is the main cause of disagreement between forest owners and farmers.

For these reasons, 27 farmers, that is, about $43 \%$ of the entire sample (Table 1), were interviewed by means of a faceto-face-structured interview. With specifically reference to farmers interviewed, 52\% are also forest owners.

Farmers were selected through an iterative process: starting with farmers known at local level, previously unknown 

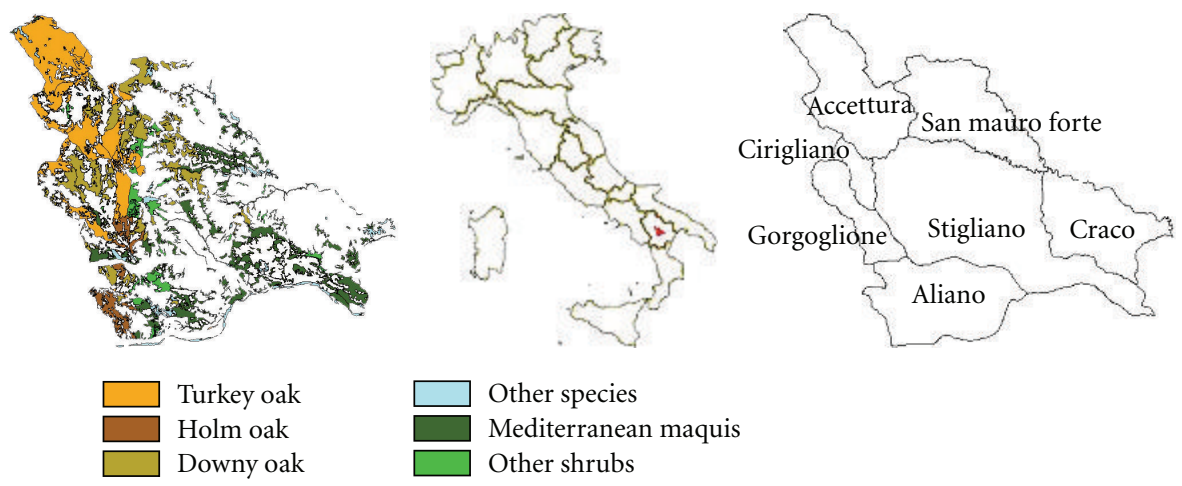

FIGURE 1: Collina Materana district: forest types (left) and municipalities (right).

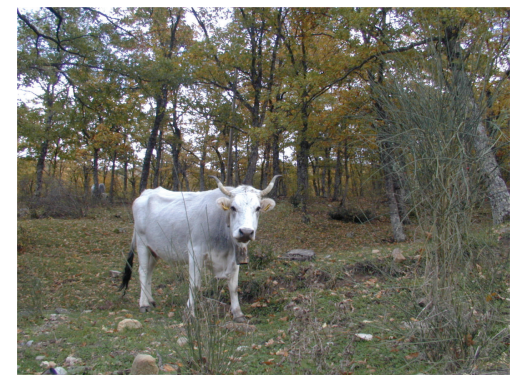

(a)

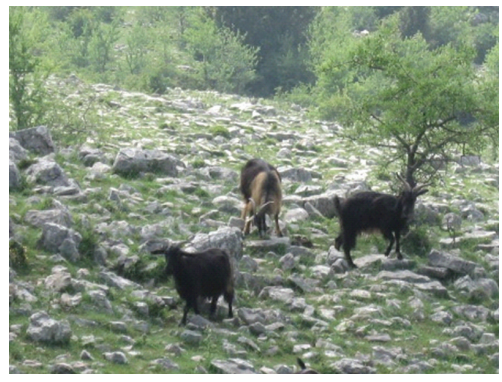

(b)

FIgure 2: Cattle and goats grazing in the Collina Materana forests.

TABLE 1: Stakeholder groups.

\begin{tabular}{lc}
\hline Stakeholder group & Representants \\
\hline Mayors & 7 \\
Comunità Montana representants & 1 \\
State forestry service & 4 \\
Associations & 4 \\
Agritourism & 5 \\
Farmers & 27 \\
Forest workers & 7 \\
Forest firms & 5 \\
Forest owners & 3 \\
\hline
\end{tabular}

respondents were also identified [16, 17], and following the first interviews, the snowball effect that ensued meant more were carried out. The main advantage of this type of sampling, known as "snowball sampling" or "referral sampling" [18], is its limited cost and sample size.

The structure of the interview is divided into thematic sections. The first section of the interview deals with the sociodemographic information of the respondents (date of birth, gender, municipality of residence, occupation, etc.). The other sections focus on certain relevant issues concerning forest management: (i) grazing and the relationship between grazing and forest, (ii) the link between farmers and the territory, and (iii) the value attributed to landscape and the perception of changes in the landscape.
The subdivision of the interview into thematic sections allows for the separate analysis of each section, as well as a final elaboration which sums the results of the three sections.

In the following paragraphs, the main questions utilised in the above-mentioned sections are described and the purpose of their formulation and the modalities with which they were structured are highlighted.

To keep the interview simple and support the respondents in their answers, authors decided that questions should be closed. Furthermore, close-ended questions are more easily analysed, and each answer can be given a number or value so that a statistical interpretation can be assessed. In some cases, a limit could be that close-ended questions may not offer the respondents choices that actually reflect their real opinions.

A large number of answers are limited to "yes," "no," and "sometimes/maybe." Other questions are formulated in a way that allows the interviewees to answer in an optionsranking scale. In other cases, the respondent has to choose from a list of preset responses.

2.2.1. Forest and Grazing Practices. The aim of the section regarding forest grazing by livestock (in particular cattle grazing) in the Collina Materana is to illustrate the existence of this local use of certain forest types, a use still practised in some areas of the Italian Apennines. These forests (mostly deciduous oak coppices and high forests) produce forage for summer grazing, supplementing the limited amount 
TABLE 2: Questions in Section 2.2.1.

(1) Is forest grazing practised in the territory where you live?

(2) In which season is forest grazing practised?

(3) What percentage of forage comes out of the forest?

(4) Does grazing damage the forest?

(5) Do you think that in your territory animal husbandry could exist without the support of the forest?

of spring-fall grassland range. The breeding of the local Podolica cattle is currently on the increase due to the quality of the beef, and the practice of forest grazing is widespread among farmers.

Knowledge of local, traditional uses in forest management represents a crucial aspect in the drafting of any planning tool. As a matter of fact, this knowledge allows critical issues (potential conflicts) to be highlighted, issues which are difficult to manage since they are more linked to cultural than to technical aspects.

The questions relating to the grazing activity are centred on assessing the spread of forest grazing and its modalities and characteristics. In particular, questions 4 and 5 are aimed at understanding whether farmers are conscious of the damage to forests that grazing could produce and whether farmers think it is possible to breed cattle without the practice of forest grazing (see Table 2).

The analysis of the main descriptive statistics of the above-mentioned questions provides an overall view of farmers' perceptions of this crucial management aspect of the Collina Materana forests. This information provides useful support in establishing future management scenarios and, particularly, in highlighting the difficulties and conflicts of present management practices and the possible solutions.

2.2.2. Link with the Territory. The link between farmers and the territory is evaluated through a set of questions which take into account both social and emotional aspects (Table 3). Husbandry activity plays an important role in the economic structure of the Collina Materana. For this reason, investigating farmers' bonds with their territory provides useful information for the development of planning alternatives which take into account the maintenance of this activity.

The first question is formulated in a way that allows the interviewees to express their bond with the territory. In order to better assess this relationship, two supporting questions have also been inserted. The first question inserted is in regard to whether the interviewees ever felt the need, in the past, to emigrate. If the answer is affirmative, then a second question is asked in order to ascertain the motivational causes, as indicated.

Three main causes were taken into consideration: lack of work, social malaise, and willingness to change. The interviewees were also given the opportunity to indicate any additional causes. A lack of work constitutes a material cause, which drives people to abandon their birthplace, whereas social malaise has a psychological connotation. A willingness to change on the part of the individual is
TABLE 3: Questions in Section 2.2.2.

(1) Do you feel a bond with the territory where you live?

(2) Have you felt the need to emigrate?

(3) Which are the main causes that may lead to emigration?

(4) Do you think that the forestry and animal husbandry sector could keep people from leaving their territory?

TABLe 4: Extreme scenarios regarding farmers' links with the territory.

\begin{tabular}{|c|c|}
\hline Scenario 1 & $\begin{array}{l}\text { The bond with the territory is strong } \\
\text { The desire to emigrate is low and, if present, is } \\
\text { mainly due to a desire for change } \\
\text { The idea that the forestry and animal husbandry } \\
\text { sector could limit emigration is strong }\end{array}$ \\
\hline Scenario 2 & $\begin{array}{l}\text { The bond with the territory is weak } \\
\text { The desire to emigrate is high mainly because of } \\
\text { social degradation } \\
\text { The idea that the forestry and animal husbandry } \\
\text { sector could limit emigration is low }\end{array}$ \\
\hline
\end{tabular}

representative of an individualistic connotation and is typical of an entrepreneurial mindset.

A change linked to the search for economic improvement leads people to leave their birthplace in the hope of starting business activities elsewhere. Should these people return to their hometowns, this would represent an important resource for the territory.

Question 4 investigates farmers' ideas of the role of the forestry and animal husbandry sector in limiting emigration and permits an understanding of the importance that they attribute to this sector from a more economic point of view.

The aggregated analysis of the questions allows for the definition of a series of situations within a continuum varying from a positive (scenario 1) to a negative (scenario 2) extreme, as reported in Table 4. A series of case records may be found between these two extremes, which have to be carefully assessed before the drawing up of the forest plan.

2.2.3. Value Attributed to the Landscape. The landscape of the Collina Materana has been deeply moulded by grazing since the Middle Ages and, still today, livestock in forests is a key element of this landscape. This section aims to examine, via a set of three questions (Table 5), the importance that farmers give to the landscape of their territory.

Question 1 investigates whether the interviewees appreciate the landscape of the territory where they live. If the answer is affirmative, then question 2 examines the features of the landscape that respondents prefer. Five main features are taken into consideration: forests, crops, pastures, villages, and ravine areas. The interviewees are also given the opportunity to indicate any additional features.

Question 3 is inserted to analyse this aspect more profoundly and concerns the level of importance the interviewees give to the landscape where they live.

This set of questions provides planners with important information for the definition of planning strategies as it 
TABle 5: Questions in Section 2.2.3.

(1) Do you like the landscape of your territory?

(2) What features of the landscape do you prefer?

(3) What importance do you give to the landscape of your territory?

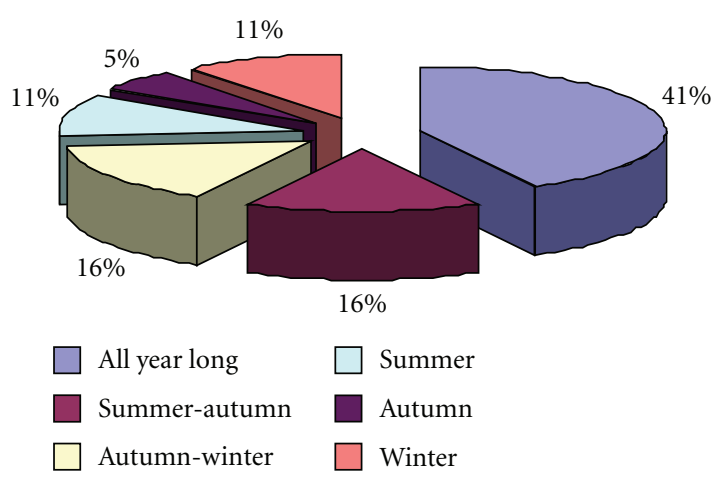

FIGURE 3: Period of the year in which forest grazing is practiced.

gives some idea of the farmers' attachment to the landscape, as well as specifying which features are considered more, or less, important in the farmers' perceptions.

\section{Results}

The information obtained from consultation with the farmers can be useful in supporting planning options and forest management. Results are firstly reported as collected in the thematic sections of the questionnaire. Afterwards, an integrated analysis of the answers provides an overall view of the farmers' perspective with respect to forest grazing and to the effect of this practice on the landscape and the territory.

3.1. Forest and Grazing Practices. Regarding the question "is forest grazing practised?", $75 \%$ of the interviewees confirm that the practice of forest grazing is spread across the territory of the Collina Materana. As shown in Figure 3, about $40 \%$ of the respondents report that cattle are in the forest all year long, not only in summer. Only for $11 \%$ of farmers is forest grazing practised mostly in summer in order to supplement the limited amount of forage available over this period.

Even though most of the farmers indicate that livestock is in the forest all year round, in the opinion of $33 \%$ of the farmers interviewed the food that animals get from the forest annually is between 1 and $10 \%$ of the total forage they need (Figure 4).

As shown in Figure 4, the farmers' opinions on this issue are quite diverse, with $11 \%$ of the respondents even indicating that animals get from the forest more than $50 \%$ of their total food annually.

Among farmers that confirm the practice of forest grazing in the Collina Materana forests, only 14\% indicate that grazing is an activity that may create damage to the forest. In order to better comprehend the results related to

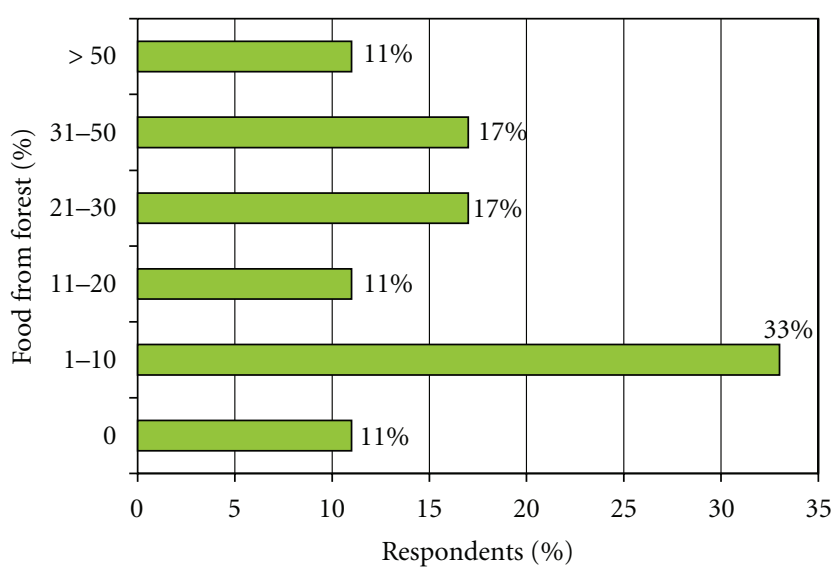

Figure 4: Food coming out from the forest.

this question, it is important to remember that the answer is linked to the perception that each single interviewee has of the situation, rather than an actual picture as reported in official statistics.

In spite of forest grazing being used considerably, in the opinion of farmers, the support of the forest is not strictly necessary in order for animal husbandry activity to be present. Regarding this last issue, almost $70 \%$ of the interviewees indicate that zootechnic activity could go on in the Collina Materana even without forest grazing.

3.2. Links with the Territory. The data related to the link with the territory show that the majority of the interviewees (91\%) feel a strong bond with the territory. In order to better investigate the results, a question on a past or present exigency of emigration was elaborated. The answers of the farmers highlight factors of malaise. As a matter of fact, $66 \%$ declare that they had taken into consideration the possibility of leaving, while $34 \%$ have never considered this option. If we consider the main problems influencing depopulation over the years, the only motive that respondents perceive as responsible for the exigency to emigrate is the lack of work $(100 \%)$.

The analysis of farmers' opinions about the forestry and husbandry sector as elements that can keep people from emigrating shows that no one, single idea prevails regarding this issue. In fact, there is a homogeneous distribution of farmers' answers among "yes" (33\%), no (33\%), and in part $(33 \%)$. This trend testifies that to some extent the forest and husbandry sector is still assumed to have an economic and social role in the Collina Materana.

3.3. Value Attributed to the Landscape. The question related to the farmers' appreciation of the landscape shows that quite the totality (99\%) of the interviewees appreciate the landscape of the territory where they live. Regarding the importance given to the landscape, $69 \%$ attribute high importance, confirming the relevant role of the landscape in the farmers' perceptions. 


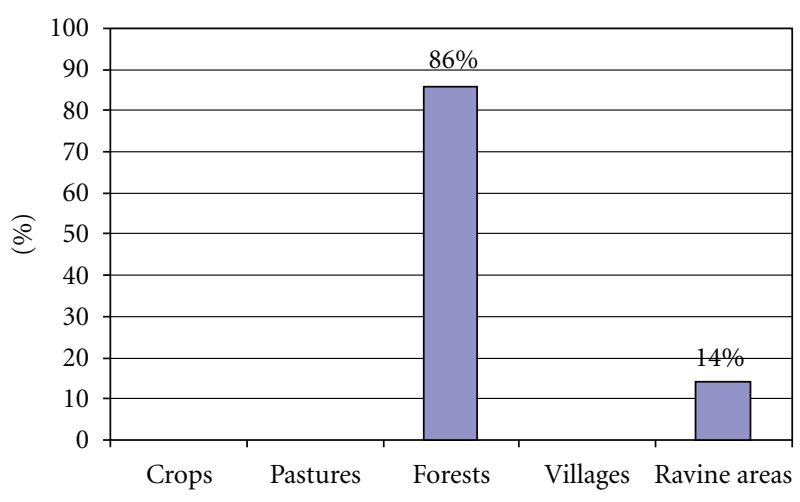

FIgURe 5: Preferred patches of landscape.

Among the main features of the landscape, farmers indicate forests $(86 \%)$ and ravine areas $(14 \%)$ as elements of the landscape that they take into consideration (Figure 5).

It is interesting to note that pastures are not a feature particularly appreciated by farmers; forests, on the other hand, are the primary components of the landscape in farmers' perceptions, confirming the strong connection between livestock and forest in the Collina Materana.

As an explorative statistical analysis on the data collected, multiple correspondence analysis (MCA), using Statistics for Windows, has been used on the categorical variables. MCA is an extension of correspondence analysis (CA) which allows to analyze the pattern of relationship of several categoricaldependent variables and providing interpretative hypotheses. As such, it can also be seen as a generalization of principal component analysis when the variables to be analyzed are categorical instead of quantitative. In other words, MCA is the counterpart of principal component analysis for categorical data [19-21].

To investigate in depth the relationship between farmers and the territory where they live, the importance assigned to the landscape and the link to the territory were associated to certain social variables of the sample.

Considering the age, three classes (20-40,41-60, and $>60$ ), have been defined. Secondly, two typologies of farmers have been considered: simple farmers and farmers who are also forest owners. Referring to the municipalities where farmers live, developed and undeveloped municipalities have been considered. The importance assigned to the landscape is based on the answers given during the interview (high/low, see Q3-Table 5). The link to the territory is based on the answers to the question "have you felt the need to emigrate?" (yes/no, see Q2-Table 3).

The MCA results highlight the fact that younger individuals who, besides being farmers, are also forest owners and who live in more developed municipalities give higher importance to the landscape (see Figure 6, percentage of inertia equal to $55.4-32.6+22.8$ ). By contrast, minor importance is given to the landscape by older farmers who live in lesser developed municipalities.

With regard to the link with the territory, the MCA shows that farmers in the intermediate age range (between 41 and

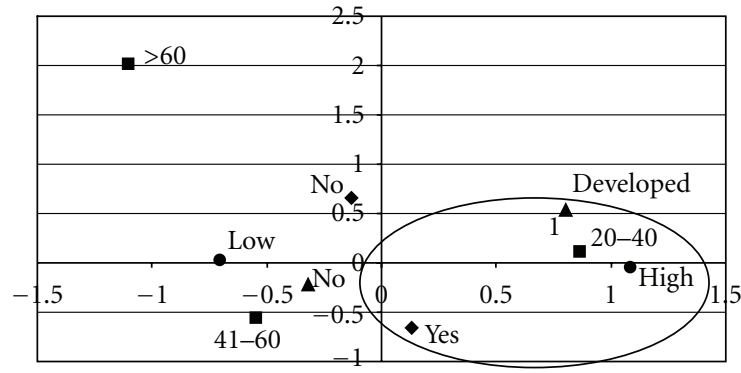

- Farmers and forest owners

- Age

- Developed/undeveloped municipalities

- Landscape importance

FIGURE 6: Multiple correspondence analysis for "landscape importance."

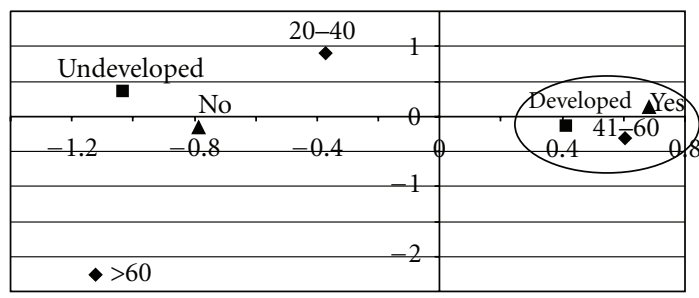

- Age

- Developed/undeveloped municipalities

$\Delta$ Exigency of emigration

Figure 7: Multiple correspondence analysis for "exigency of emigration."

60) who live in more developed municipalities have taken into consideration the possibility of leaving (see Figure 7, percentage of inertia equal to $58.5-33.1+25.4$ ).

\section{Discussion and Conclusions}

Research carried out has revealed indications potentially useful for forest planning on a landscape level.

In particular, interviews with farmers have brought to light a number of aspects that will allow for a better understanding of the territorial context and the dynamics at work. These aspects include elements that planning cannot disregard:

(i) forest grazing is a very important, traditional activity; more than just a question of economics and productivity, it is seemingly bound to ancient forms of management, deeply rooted in the local culture. Forest grazing is, in fact, practised all year round and not only during the summer season, when the scarcity of other resources renders whatever forage the forest may produce particularly valuable. Approximately one-third of the interviewees maintain that the quantity of forage obtained from the forest is, 
in effect, rather limited, and as much as $70 \%$ of the interviewees maintain that zootechnic activity in the region could be continued even without forest grazing. Despite this fact, the forest is being utilised largely for grazing, as well as it is considered one of the most important components of the local landscape, to the extent that one could even speak of a form of "cultural grazing;"

(ii) in general, the farmers maintain strong ties with their own territory and their own traditions. Planning needs to take these values into account: ignoring or underestimating them will undoubtedly bring the parties into conflict; by contrast, should the convictions of these farmers be opportunely valued, such convictions, deeply rooted in the population, may well transform themselves into opportunities for development in the territory;

(iii) there exists a particularly reliable category of farmer that, if suitably and timeously included in the process, could make an active contribution to the sustainable development of the territory: this category refers to those farmers who attribute to the forestry and zootechnic sector an economic role sufficiently significant to halt the outmigration, young individuals, who, very often, are also owners of forests, and who reside in communities where there is increased potential for economic development.

If, therefore, on the one hand, it would seem clear that planning has to acknowledge, amongst the forest's many functions, also that of "hosting" grazing, on the other hand it cannot be denied that, from a technical point of view, this practice does indeed have a negative effect on the forest's ecosystem. Only 14\% of those interviewed, however, acknowledge the existence of such problems, despite these being evident in all of the forests in the region. The unawareness of farmers about negative effects of forest grazing is a further evidence of the fact that this practice is realized without any form of planning; farmers leave their animals in the forest without a consciousness of the real effects of this activity.

Continued forest grazing, carried out excessively, is very closely connected to the widespread presence of forest formations degraded with irregular structures, and species reduction and simplification. The widespread phenomenon of soil compaction and damage caused by animal paths can likewise be imputed to an overabundance of livestock. To ensure any successful, future management, therefore, it is recommended that suitable plans for grazing be drawn up, plans that allow for grazing to be rationalised, and for livestock to be scaled down and managed in a sensible manner, whilst at the same time endeavouring to modify current, unrestricted grazing techniques by means of other, more rational techniques such as those that provide for a rotation of animals between sectors. The grazing of bovines has the potential to represent a resource for the territory provided the number of animals is appropriate and proportionate to the amount of foraging available. Only on these conditions can the management of these forests be adapted for multiple use, with grazing fitting well into a pattern which includes watershed maintenance, timber production, biodiversity conservation, and recreation. Needless to say, this requires the involvement of the farmers, starting with those who have already proved themselves to be more sensitive, more open, and more dynamic to the cause.

We would like to conclude by emphasising the usefulness of studies in perception, in order to support forest management. Planners, managers, and decision makers are seldom aware of the complex range of meanings and values attributed by individuals to the forest, or of the strong bonds that tie such individuals either to the territory to which they are linked or the landscape that characterises such places. Mountain communities that are vital and thriving are a prerequisite for the conservation of the landscape and the safeguarding of those many and inherent values that form part of the culture and local traditions. There can be no better way to achieve this than by involving the population in the management of the territory; an excellent first step would be to be mindful of the needs and expectations of the people, whilst fully appreciating the values they attribute to the forest.

Another objective of these researches on a landscape scale using the interview method is to "measure" qualitative data and value judgements, in order to render the results more objective and comprehensible to those in charge of planning, the intention being on the one hand to facilitate decisions and on the other, communication.

\section{Acknowledgments}

This work is part of the Forest Landscape Plan of the Comunità Montana Collina Materana, realised within the frame of activities established by the Agreement between the Agricultural Research Council (CRA) and the INEAHeadquarters in Potenza, Italy. The working methodology was elaborated by CRA within the MIPAF "Ri.Selv.Italia"Subproject 4.2 "Geographic informative system for forest management." Ri.Selv.Italia is a national multiyear research project in the forest-wood-environment sector "oriented to problem solving," promoted by the Ministry of Agriculture and Forests in concert with Regions. The authors have contributed to this study and paper in equal parts.

\section{References}

[1] G. M. Hickey, "Regulatory approaches to monitoring sustainable forest management," International Forestry Review, vol. 6, no. 2, pp. 89-98, 2004.

[2] G. M. Hickey, J. L. Innes, and R. A. Kozak, "Monitoring and information reporting for sustainable forest management: a regional comparison of forestry stakeholder perceptions," Journal of Environmental Management, vol. 84, no. 4, pp. 572585, 2007.

[3] European Commission, “"Natura 2000” e foreste: sfide ed opportunità. Guida interpretativa," Ufficio delle pubblicazioni ufficiali della Comunità Europea, Lussemburgo, pp. 107, 2003.

[4] FAO-ECE-ILO, "Public participation in forestry in Europe and North America. Report of the FAO/ECE/ILO Joint Committee 
Team of Specialists on Participation in Forestry," Working Paper 163, Sectorial Activities Department, International Labour Office, Geneva, Switzerland, 2000.

[5] Y. Kazemi, "Instruments de la participation publique: quelques repères théoriques sur la notion de participation publique dans le cadre de l'article 18, alinéa 3 de l'Ordonnance fédérale sur les forêts. Document préparatoire au cours SSF/CRIFOR/CSAF," Instruments de la Participation Publique. Olten, Switzerland, 2001.

[6] M. G. Cantiani, D. Bettelini, and S. Mariotta, "Participatory forest planning: a chance of communication between forest service and local communities," in Proceedings of the International Conference FAO/ECE/ILO "Forestry meets the Public", pp. 249-263, Rüttihubelbad, Switzerland, October 2001.

[7] A. S. Cheng, L. E. Kruger, and S. E. Daniels, "“Place” as an integrating concept in natural resource politics: propositions for a social science research agenda," Society and Natural Resources, vol. 16, no. 2, pp. 87-104, 2003.

[8] E. O'Brien, "A question of value: what do trees and forests mean to people in Vermont?" Landscape Research, vol. 31, no. 3, pp. 257-275, 2006.

[9] V. F. Schmitehusen and S. Wild-Eck, "Uses and perceptions of forests by people living in urban areas findings from selected empirical studies," Forstwissenschaftliches Centralblatt, vol. 119, no. 6, pp. 395-408, 2000.

[10] M. A. Tarrant and H. K. Cordell, "Amenity values of public and private forests: examining the value-attitude relationship," Environmental Management, vol. 30, no. 5, pp. 692-703, 2002.

[11] D. Trakolis, "Local people's perceptions of planning and management issues in Prespes Lakes National Park, Greece," Journal of Environmental Management, vol. 61, no. 3, pp. 227 $241,2001$.

[12] O. Rackham, Ancient Woodland: Its History, Vegetation and Uses in England, Edward Arnold, London, UK, 1980.

[13] O. Rackham, The History of the Countryside, Joseph Malaby Dent, London, UK, 1986.

[14] I. D. Rotherham, "The implications of perceptions and cultural knowledge loss for the management of wooded landscapes: a UK case-study," Forest Ecology and Management, vol. 249, no. 1-2, pp. 100-115, 2007.

[15] F. Vera, Grazing Ecology and Forest History, CABI Publishing, Oxon, UK, 2000.

[16] S. R. Harrison and M. E. Qureshi, "Choice of stakeholder groups and members in multicriteria decision models," Natural Resources Forum, vol. 24, no. 1, pp. 11-19, 2000.

[17] M. Hislop, Involving People in Forestry: A Toolbox for Public Involvement in Forest and Woodland Planning, Forestry Commission, 2004.

[18] R. Hair, P. Bush, and D. J. Ortinau, Marketing Research: A Practical Approach for the New Millennium, McGraw-Hill, Boston, Mass, USA, 2000.

[19] H. Abdi and D. Valentin, "Multiple correspondence analysis," in Encyclopedia of Measurement and Statistics, N. J . Salkind, Ed., pp. 651-657, Sage, Thousand Oaks, Calif, USA, 2007.

[20] B. Le Roux and H. Rouanet, Geometric Data Analysis, From Correspondence Analysis to Structured Data Analysis, Kluwer Academic Publishers, Dordrecht, The Netherlands, 2004.

[21] M. Greenacre and J. Blasius, Eds., Multiple Correspondence Analysis and Related Methods, Chapman \& Hall/CRC, London, UK, 2006. 

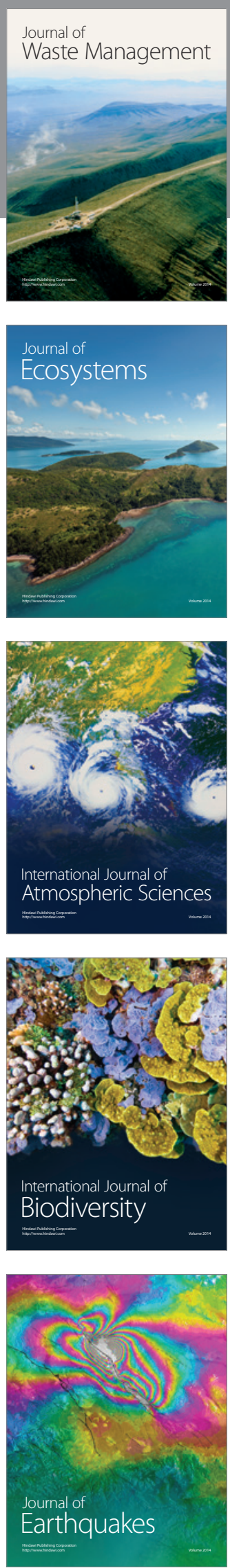
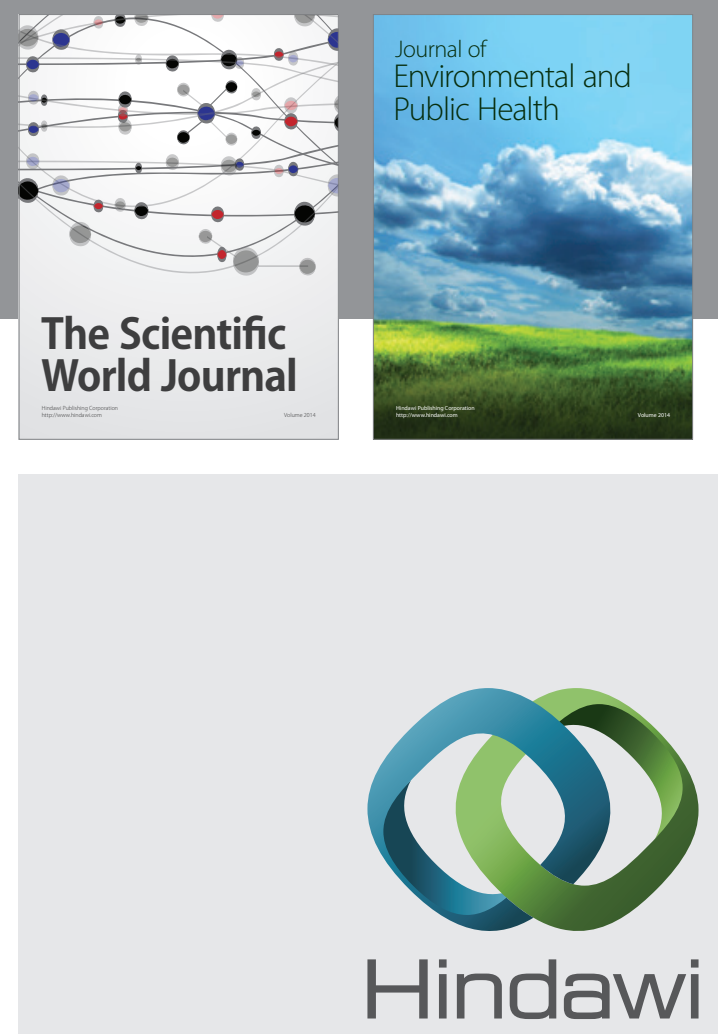

Submit your manuscripts at

http://www.hindawi.com
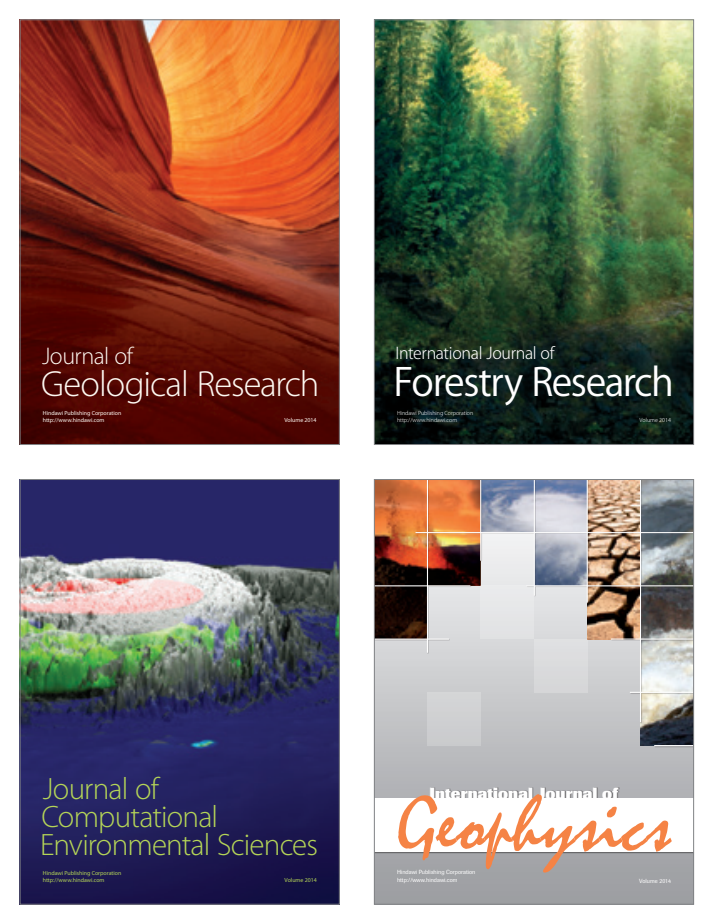
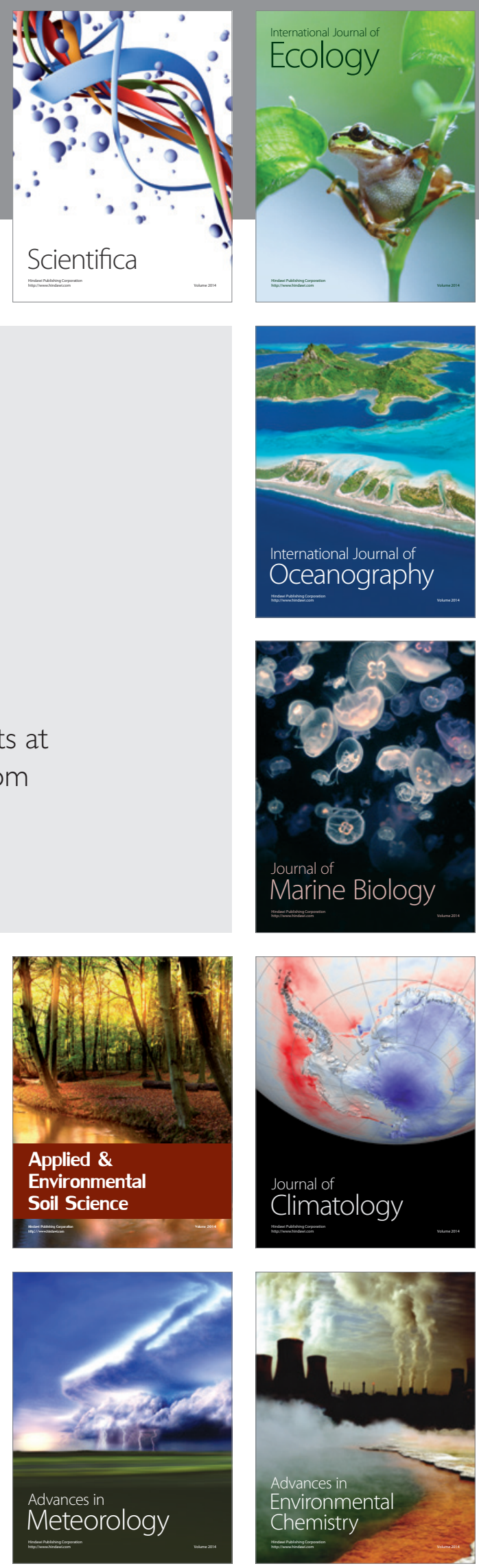